\title{
TEXTURE ANALYSIS OF MILD STEEL SOLDERING ROD
}

\author{
${ }^{1}$ Salim MESSAOUDI, ${ }^{1}$ Toufik DJIMAOUI, ${ }^{1}$ Mosbah ZIDANI, ${ }^{1,2}$ Mohamed Chaouki NEBBAR, \\ ${ }^{3}$ Marie Hélène MATHON, ${ }^{4}$ Anne-Laure HELBERT, ${ }^{4}$ François BRISSET, ${ }^{4}$ Thierry BAUDIN \\ ${ }^{1}$ Mohamed Khider Biskra University, Laboratory of Energy and materials Engineering, Faculty of Science \\ and Technology, Biskra, Algeria, salim messaoudi@yahoo.fr \\ ${ }^{2}$ Center for Scientific and Technical Research in Physical-Chemical Analysis (CRAPC) - BP 384, Bou-Ismail, \\ Tipaza, Algeria \\ ${ }^{3}$ Léon Brillouin Laboratory, CEA(DSM-DRECAM) - CNRS, CEA Saclay, Gif sur Yvette, France, EU \\ 4ICMMO, SP2M, Univ Paris-Sud, Université Paris-Saclay, UMR CNRS 8182, Orsay Cedex, France, EU
}

https://doi.org/10.37904/metal.2019.686

\begin{abstract}
In this study we present an analysis of the evolution of the texture of a mild steel welding rod from the initial state to the welded state. And thus show the effect of drawing on the texture of the welded metal.

The analysis of the initial state reveals the presence of a slight texture of the ferritic phase at the periphery. Several hypotheses are emitted but the main cause of the presence of the fiber $<110>$ has not yet been identified.

The first deformation leads to the development of the fiber $<110>$ over the entire section of the drawn wire. At this deformation level, the pearlitic phase does not appear to undergo any apparent deformation and the quantitative analysis shows a homogeneous distribution of the texture between the core and the periphery of the wire. After the second deformation, the perlite undergoes a very visible deformation under the light microscope and the fiber $<110>$ becomes more intense in the core than on the periphery of the wire.

The examination of the texture of the welded state exhibits another texture composed of three $<100>$, $<110>$ and $<111>$ fibers whose ratios vary according to the observed angle. The chemical analysis reveals presence of elements of coating of a rod in a matrix of welded metal. It has been found that the drawn state of the rod and the manner in which welding is performed influence the texture of the deposited metal, but their separate effects need to be more inspected.
\end{abstract}

Keywords: Welding rod, deformed phase, deformation texture, metal fiber, deposited metal

\section{INTRODUCTION}

The analysis of the texture of the welding rod generally goes through the analysis of the initial state (material called wire rod) and the drawn state [1-3]. This approach is undertaken in some works on steels [4,5] and even on other materials designated for functions other than welding. According to the literature the texture of the cold drawn wire is essentially dominated by the ferritic phase fiber $\langle 110\rangle$ [1-4]. The interest of this study is to complete this approach by examining the effect of the wire drawing texture on the final texture of the weld.

In this work, the weld analyzed, is not the assembly area between two pieces as is the custom, but it is the molten state of the rod itself obtained by welding in a suitable mold, that we will designate later the deposited metal. The welding (the deposition) is carried out in a mold, of standardized dimensions, by carrying out parallel back and forth welding, in the manner of plowing furrows.

\section{STUDIED MATERIAL}

The material studied is a mild steel wire made by the hot rolling process, known as wire rod; its chemical composition is recorded in the Table 1 below. 
Table 1 Chemical composition of the studied material

\begin{tabular}{|c|c|c|c|c|c|c|c|c|c|}
\hline Element & $\mathrm{C}$ & $\mathrm{Cu}$ & $\mathrm{Mo}$ & $\mathrm{Mn}$ & $\mathrm{Ni}$ & $\mathrm{Si}$ & $\mathrm{P}$ & $\mathrm{Cr}$ & $\mathrm{Fe}$ \\
\hline Average (wt\%) & 0.069 & 0.014 & 0.036 & 0.42 & 0.021 & 0.078 & 0.009 & 0.016 & balance \\
\hline
\end{tabular}

The wire rod is cold-drawn under industrial conditions using lubrication; the drawing strain $\varepsilon_{i}$ is calculated by the equation (1), which is completely different from that reported in some works on drawn steel $[6,7]$.

$\varepsilon_{i}=\frac{S_{0}-S_{i}}{S_{0}}$

Where:

$S_{0}$ - the section of the wire rod $\left(\mathrm{mm}^{2}\right)$

$S_{i}$ - the section of the drawn wire $\left(\mathrm{mm}^{2}\right)$

\section{INITIAL STATE}

\subsection{Metallographic analyzes}

As expected, this analysis reveals the ferritoperlitic microstructure of the wire rod. In Figure 1, we can see a vast matrix (phase) ferritic in which are dispersed pearlitic grains. The analysis of the grain size shows that the space of the ferritic matrix is composed of coarse grains. However, it is the small grains that make up the most pearlitic volume.

A closer examination of the microstructure shows that the morphological orientation (arrangement) of the grains, of the two phases, does not seem entirely isotropic. In the ferritic phase, non-spherical shaped grains appear to be stored and aligned along the axis of the wire. As for the grains of the pearlitic phase, they exhibit a shape drawn parallel to the axis whose lamellae are aligned perpendicular to the axis. This result indicates that the microstructure of the wire rod has some anisotropy in the alignment (arrangement) of the grains.

Although at the core and periphery of the wire rod, the microstructural analysis carried out shows no disparity between these two zones.
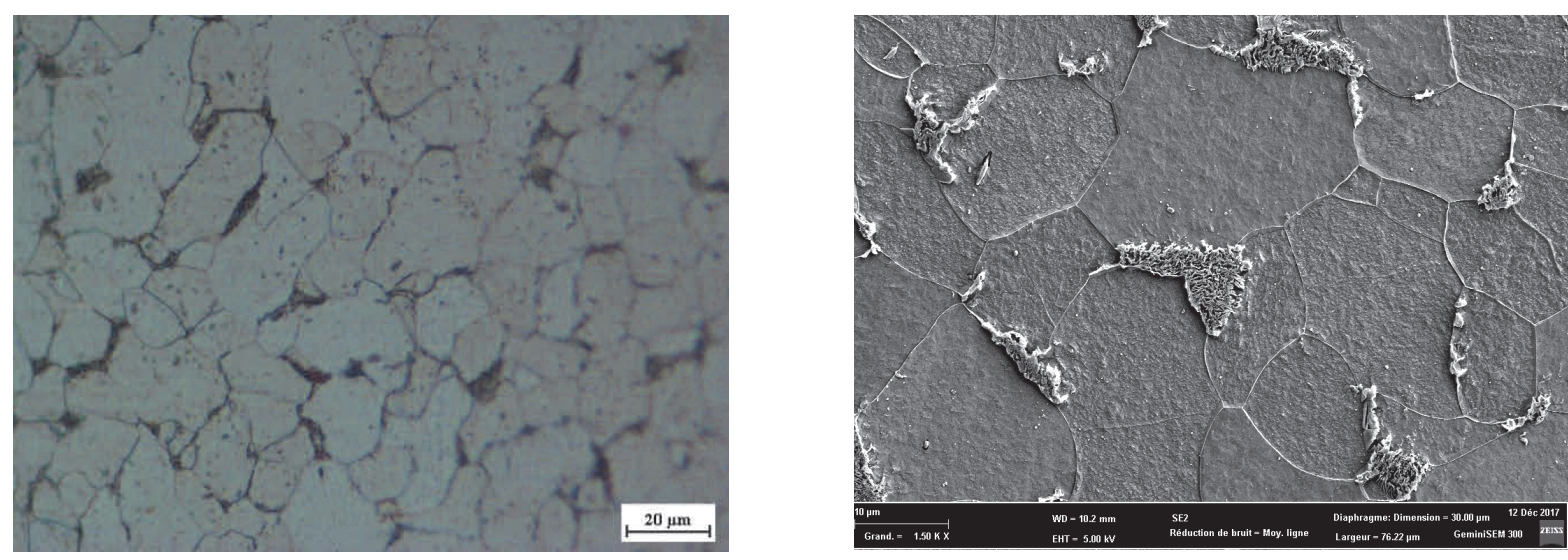

Figure 1 Microstructures of longitudinal sections seen at M.O and M.E.B respectively

\subsection{EBSD analyzes}

EBSD analysis was performed on the ferritic phase only; for this phase, the desired textures are generally limited to the three families $\{111\},\{110\}$ and $\{001\}$ and the axis of the wire serves as a reference for the texture.

Figure 2 illustrates the EBSD mappings of $\{111\},\{110\}$, and $\{001\}$ textures at the core and periphery of the wire rod [8]. At the level of the heart we can say that none of the sought-after textures seems dominant. This 
observation reflects a random and isotropic state of the crystalline orientation of the grains of the heart. On the other hand, on the cartography of the periphery, one notices a certain dominance of the colors drawing towards the $\{110\}$ family. This result indicates the presence of a texture at the periphery of the wire rod.
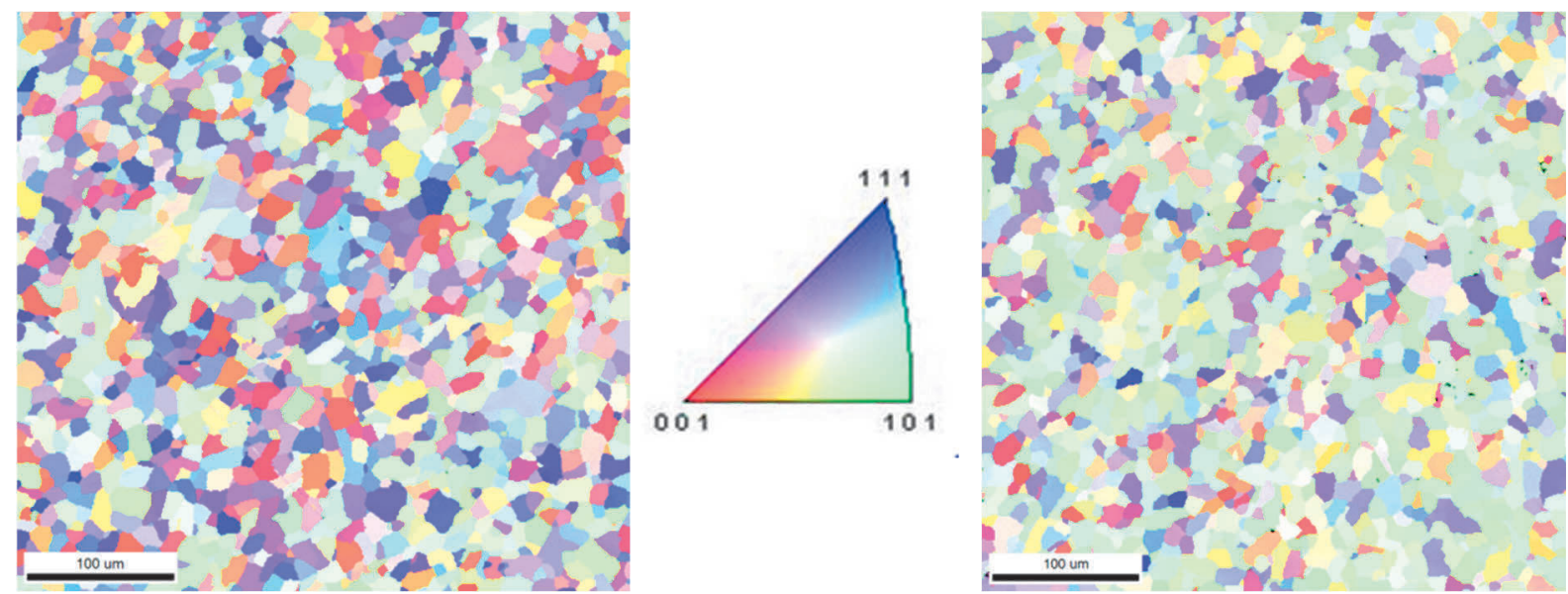

Figure 2 EBSD maps of the core and periphery of the wire rod [8]

These two observations are then established and confirmed by the pole figures and by the distribution functions of the crystalline orientations illustrated in Figure 3.

The presence of the fiber $\langle 110\rangle$ at the periphery of the wire rod can be attributed more to the pre-deformation induced by the hot rolling during the elaboration of the wire; as well as the microstructural anisotropy of the ferritic grains and the pearlitic grains.
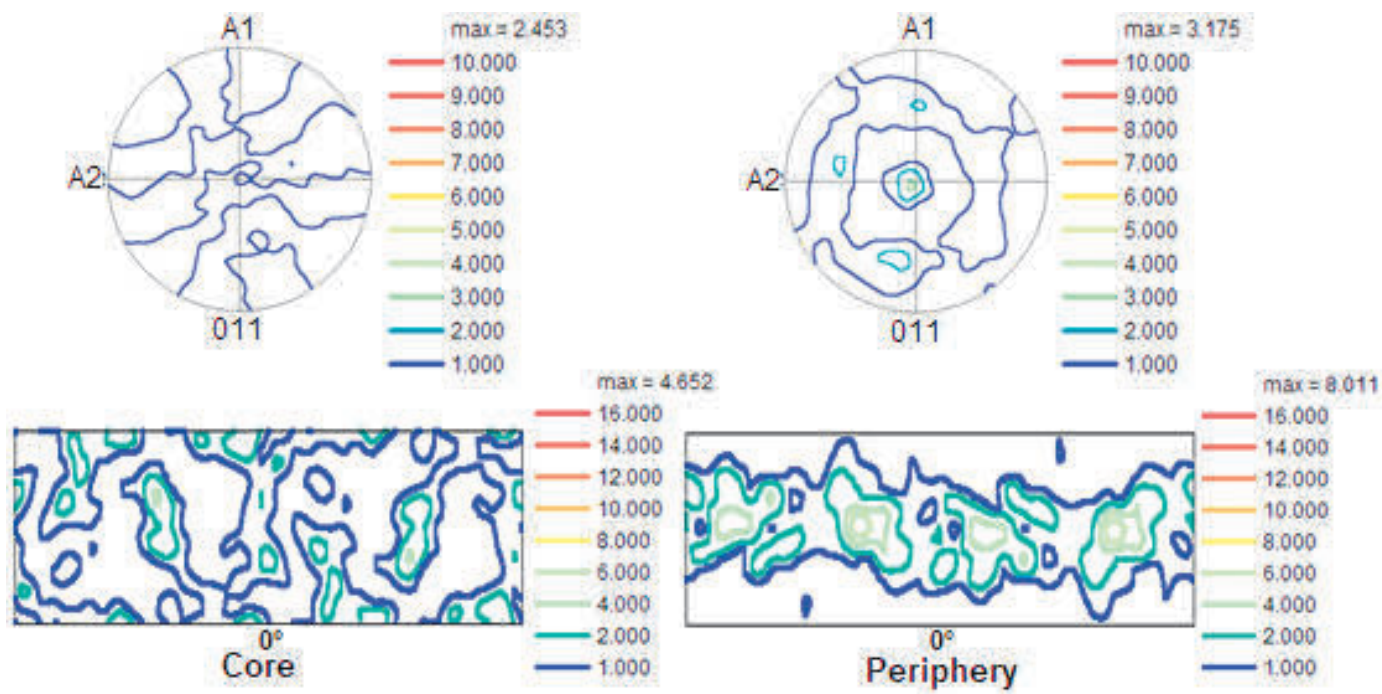

Figure 3 Pole Figures and Crystal Orientation Distribution Functions (ODF) in the Core and Periphery of the wire rod

In previous works [9] made on a pearlitic steel intended for the same use, we did not have the same result in periphery. While each steel is produced by a different manufacturer, the manufacturing process was the same for both manufacturers.

For this steel, the texture $\langle 110\rangle$ is well present at the periphery of the wire rod and it is believed that it is caused by hot rolling during the preparation. Similar results have been obtained by Schuman on extra-mild steel [1]. 
We noted that the chemical analysis carried out (Table 1) shows a steel of very good purity of chemical elements such as manganese, silicon and sulfur. This eliminates the search for any carbide other than cementite that can form. It is assumed that the excess of any element is dissolved in the ferritic matrix.

\section{DRAWN STATE}

Figure 4 illustrates the crystallographic orientation distribution functions of the drawn wires of the $<110>$ fiber only.

The first observation that can be made is the appearance of the fiber $<110\rangle$ at the center of the drawn wires at $\varepsilon=27 \%$. However, this result does not mean that exactly at this deformation $(\varepsilon=27 \%)$ the fiber begins to appear in the heart of the drawn wire. But it is rather the opposite; in view of its intensity (by contribution to that of the periphery) this fiber could be formed too much lower deformations. And according to the literature [3], this texture would be composed of a conventional fiber $\langle 110\rangle$ related to the tensile effect and a circular fiber $\langle 110\rangle(110)$ due to the shear forces in the dies on the surface of the wire.

The second observation that can be drawn is that, during wire drawing, the fraction of this fiber becomes larger in the center wire than on its periphery. This allows us to say that the wire drawing leads, little by little, to the development of the fiber $\langle 110\rangle$ from the periphery to the core of the drawn wire. In the case of drawing, the stresses of the deformation are concentrated from the surface (the periphery) to the center (the heart) of the drawn wire. At the beginning of the deformation, the intensity of the stresses is greater at the periphery than at the center of the wire, but beyond a certain deformation this tendency is reversed and the intensity of the stresses becomes more substantial on the grains of the heart than on those of the periphery. This explains the inverse ratio of the fraction of the fiber $\langle 110\rangle$ between the periphery and the core during drawing. Certainly this interpretation lacks direct measurements; however, it is in perfect correlation with the measurements made by Yue and al on a pearlitic steel [5]. On the other hand, it is entirely different from that enunciated by Abdallaoui [3] which stipulates that the wire deforms in the core at the beginning of the drawing, and then the deformation on the surface takes the relay at the end of drawing.

This result leaves us to conclude that the fiber $<110>$ appeared on the periphery of the wire rod is well resulting from a deformation present during the elaboration of the wire. And the initial texture of the wire influences the process of any following deformation. This result is in perfect agreement with the work of Arnaud Pougis [10].

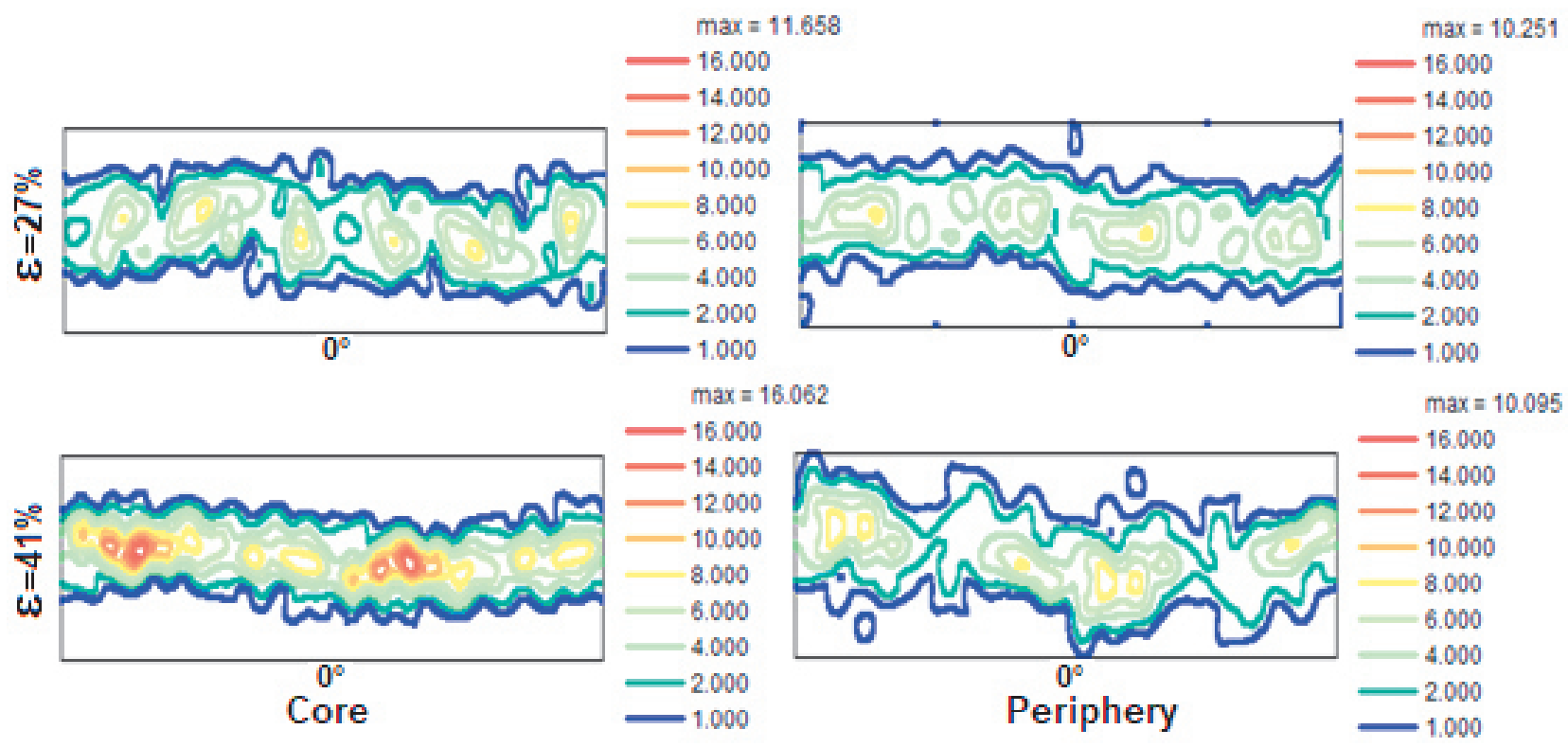

Figure 4 ODF of the core and periphery of drawn wire 


\section{DEPOSITED METAL}

For this state it is the analysis of pole figures that illustrates much more clearly the redistribution of the desired fibers. Note the presence of the three desired fibers $\langle 100\rangle,\langle 110\rangle$ and $\langle 111\rangle$ with low intensities. For the zone shown in Figure 5, it is the fiber $\langle 111\rangle$ which exhibits a signal of higher intensity. But in some areas, the three families appear with the same intensities. This observation indicates the presence of a composite texture in the deposited metal. The change of the angle of analysis, between the $0^{\circ}$ and $90^{\circ}$, resulted each time in the same result, but with another fiber more intense according to the observed angle. This alternation in the results leaves us perplexed as to the interpretation.

Through this study, we wanted to see the effect of the texture of the welding rod on the formation of the welding texture (deposited metal). But our way of proceeding has not clearly clarified this point.
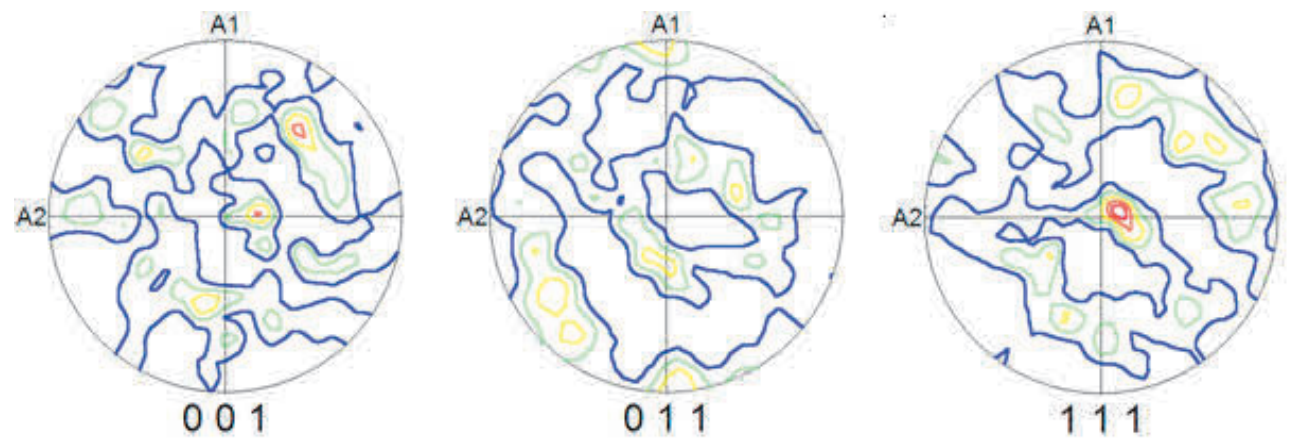

$\max =2.177$

Figure 5 The pole figures of the families $\{110\},\{001\}$ and $\{111\}$ of the deposited metal

\section{CONCLUSION}

The interesting results that can be extracted from this study are the following:

- The texture- $\langle 110\rangle$ initially present on the wire rod is the result of the predeformation caused by hot rolling during the elaboration of the wire.

- $\quad$ The presence of an initial texture on the machine wire has not allowed the appearance of new fibers during drawing.

- The wire drawing leads to the development of the fiber- $<110>$ over the whole section of the drawn wire.

- $\quad$ This development is pat pat from the periphery to the heart according to applied strain.

- $\quad$ For this steel, there is a deformation close to $27 \%$ from which the fraction of the fiber $\langle 110\rangle$ in the core of the wire becomes larger than at the periphery.

- The texture of the deposited metal is composed of the three families of fibers $\langle 111\rangle,\langle 110\rangle$ and $<100\rangle$ with a majority tendency for the fiber $<111>$ in all the zones analyzed.

- The step taken has not made it possible to see in a clear and convincing way the effect of the texture of the drawing on the formation of the texture of the deposited metal.

\section{REFERENCES}

[1] SCHUMAN, C. Etude de l'evolution de la texture cristallographique d'aciers extra-doux au cours du trefilage et d'une operation particuliere de laminage. Determination des contraintesi nternes. Doctoral Thesis. France: Université de Metz, 1994. p. 122.

[2] MONTESIN, T. Influence des conditions de trefilage sur la texture cristallographique et sur les proprietes mecaniques des fils fins: application au steelcord. Doctoral Thesis. France: Université de Metz, 1991. p. 189.

[3] ABDELLAOUI, A. Etude de la texture cristallographique de fils d'acier perlitiques en fonction des conditions de trefilage: influence sur les proprietes mecaniques. Doctoral Thesis. France: Université de Metz, 1995. p. 179. 
[4] FENG, F., LICHU, Z., XIANJUN, H., XUEFENG, Z., YIYU, T., ZONGHAN, X. and JIANQING, J. Microstructure an mechanical properties of Cold-Drawn pearlitic wires affect by inherited. Materials and Design. 2015. vol. 79, pp. 60-67.

[5] YUE, H., SONG, X., WEI, S., JIANMIN, L., XUANMING, J. and WEN, Y. Effect of microstructure evolution on anisotropic fracture behaviors of cold drawing pearlitic steels. Materials Science \& Engineering A. 2017. vol. 683, pp. 153-163.

[6] CHAKRABORTYA, J., GHOSHA, M., RANJAN, R., DASA, G., DASC, D., and CHANDRAD, S. X-ray diffraction and Mössbauer spectroscopy studies of cementite dissolution in cold-drawn pearlitic steel. Philosophical Magazine. 2013. vol. 93, no. 36, pp. 4598-4616.

[7] BROCHERS, C. and KIRCHHEIM, R. Cold-drawn pearltic steel wires. Progress in Material Science. 2016. vol. 82, pp. 405-444.

[8] DJIMAOUI, T. Etude de comportement structural et mécanique des fils tréfilés en acier doux destinés pour la fabrication des électrodes de soudure à TREFISOUD. Doctoral Thesis. Algeria: Université de Biskra, 2019. p. 97.

[9] ZIDANI, M., MESSAOUDI, S., BAUDIN, T., SOLAS, D. and MATHON, M. H. Deformation textures in wire drawn pearlitic steel. International Journal of Material Forming. 2010. vol. 3, pp. 7-11.

[10] POUGIS, A. Affinement de microstructures de métaux par des déformations plastiques extremes. Doctoral Thesis. France: Université de Lorraine, 2013. p. 265. 